\title{
Oral Bacteria Contribution in Wine Flavor Perception
}

\author{
Davide Frumento ${ }^{1,2^{*}}$ \\ ${ }^{1}$ Department of Health Sciences, DISSAL, University of Genova, Italy \\ ${ }^{2}$ Department of Biomedical and Clinical Science L. Sacco, University of Milan, Italy
}

Submission: April 18, 2018; Published: June 27, 2018

*Corresponding author: Davide Frumento, Infectious Diseases Unit, Department of Health Sciences, Hospital San Martino, Largo Rosanna Benzi 10, 16132 Genova GE, Italy, Tel: +393334310322; Email: davide.frumento@edu.unige.it

\begin{abstract}
Background: Recently, one of the most debated problems within the wine tasters community, is whether personal biological variability can affect the wine flavors sensing or not. In other words, can wine aroma perception be considered as an absolute truth?

Methods: The present paper demonstrates that, relying on proven data, that the answer is no. Few research about this topic has been published, but data clearly show evident biochemical intravariabilities, mostly based on oral bacteria enzymes secretion.

Results: Individual variability in receptors expression dramatically affect this process, but the combination between both oral bacteriaderived and salivary enzymes seems to be the pivotal factor able to dissociate aromatic compounds from sugars and allow them to pass from liquid to gaseous phase, so that, following the Retropharyngeal Path, they can be sensed by olfactory neurons placed at tectory level, that can however express receptors in a variable and genetically-based manner.
\end{abstract}

Conclusion: The aim of the present work is that of provide tools to rethink wine tasting, constructing an evidence-based perspective in the broad world of wine.

Keywords: Microbiota; Bacteria; Wine; Enzymes

\section{Introduction}

Under a scientific point of view, wine is a microbiologically originated molecular cocktail. Grape's chemical composition can be considered the very beginning of wine flavor and it has been broadly investigated, in order to understand the complex texture of the volatile compounds at the base of wine aroma. Wine features are generally summarized as visual, olfactory and gustative, contributing to form the general beverage aroma [1] that roots into different molecules classes dissolved into the wine solution. They can be categorized as varietal aromas (from grape), fermentative aromas (from both malolactic and alcoholic fermentation) and ageing aromas (from storage/ageing conditions). Most wine aroma molecules, including the varietal ones, are synthesized or secreted during the productive process and derived from bacterial metabolic activity. Moreover, it has to be said that wine fermentation takes place thanks to a multispecies machinery and the different involved microorganisms can be assembled in the wine grape microbiome [2,3]. This bacterial populations origin from vineyards and their composition and activity are therefore dependent on grape variety, agronomical practices and geographic feature, giving to enological specialists a brand-new concept of terroir [4-6]. With that in mind, it is not far-fetched to hypothesize that wine aroma can somewhat be predicted on the base of grape's microbiological profile [3]. It is generally known that most of the fermentation-derived molecules have high sensory thresholds, so that they cannot contribute as single compounds to the give the beverage a clear sensorial distinction, but their combination makes up an aroma matrix. On the other hand, most of the sensory incisive molecules can be found at low concentrations in both wines and grapes and thanks to their minimal perception thresholds they possess a decisive impact on the general wine aroma [7].

\section{Lactic Acid Bacteria}

Lactic acid bacteria are a pivotal group in the context of wine production, since they carry the machinery for decarboxylation of malic acid to lactic acid, i.e. the malolactic fermentation, that in the most of cases occurs after the alcoholic one. This key role process, needed mostly for red wines, makes them more palatable. In fact, it greatly reduces the malate-derived sour taste and gives both enhanced aroma texture and microbiological firmness. Although Oenococcus oeni is the main species found in spontaneous malolactic fermentations, certain Lactobacillus strains (e.g. Lactobacillus plantarum) have been proved to be fitting into complete this peculiar fermentation [8-10]. Moreover, malolactic fermentation often varies the sensory features of wines by secreting diacetyl (2,3-butanedione) and other citrate-derived carbonyl molecules at rather high concentrations, contributing to the buttery aroma within the beverage $[11,12]$. 


\section{Ageing}

Lastly, ageing is a crucial step in the final taste-olfactory features of wines and, although it is generally related to red ones, is now also linked to both rosé and white wines. Ageing the beverage in oak barrels infuse it with wood-related aromatic compounds mainly furfural molecules [13]. During this step a whole variety of microbial-derived substances, (e.g. polysaccharides, peptides or free amino acids) contribute too [1416]. They come from lees (namely both dead bacteria and yeasts) that contains active enzymes that act on wine even during storage, in fact they are usually intentionally used within the wine industry [17-19]. This process does not exclude spoilage because of the presence of ethanol-tolerant microorganisms (e.g Brettanomyces bruxellensis) that can synthesize elevated quantities of ethyl phenols, which give wine the undesirable medicinal and meaty flavors [20]. In this context, this review aims to integrate the current knowledge about the role of microorganisms, mainly yeasts and lactic acid bacteria, in wine aroma and their potential use as biological tools to enhance wine quality. Furthermore, the conversion of aroma compounds by oral microbiota during wine consumption is considered. Finally, the advent of promising opportunities and challenges allowed by genomics on wine yeasts and bacteria research is also discussed.

\section{Oral Bacteria Contribution in Wine Flavors}

Wine flavors free their selves once beverage is spilled in a glass, but the perception of them greatly differs between individuals, mainly due to differences in taste buds, olfactory sensitivity (i.e. receptors expression), allergies, smoking habits and sensorial memory [21]. It has to be said that a subtler set of factors works to personalize aroma perception, thanks to the different sets of oral bacteria present in each individual. It has been in fact demonstrated that, in humans, microbiota's alpha factor significantly varies between subjects, relying on a multifactorial basis [22]. To be olfactory sensed, molecules must be pass from liquid to gas phase either in the glass or in mouth, but they are usually bound to sugar molecules. Interestingly, human saliva carries enzymes that act breaking bonds with sugars, for instance salivary amylase [23], and as soon as wine mixes with saliva, such chemical reactions take place and the newly formed beverage's gaseous phase can follow the so called Retropharyngeal Path and be sensed as a smell [24]. Saliva causes other variations on wine molecules [25] due to other enzymes and proteins, in fact the basic acid reaction that occurs when wine $\mathrm{pH}$ from 3 to 4 [26] mixes to saliva fairly neutral $\mathrm{pH}$ [27] causes a shift in chemical form of many molecules potentially bringing them from un-aromatic to aromatic or the other way around. This could be the reason that explains why a wine's flavor perception is different after swallowing if compared with the olfactory exam one. Importantly, saliva composition can broadly vary. According to [28], while tasting and evaluating a white wine, saliva belonging to obese individuals released fewer aroma molecules if compared with normal weight people, in fact esters and acetates were released with a reduction ranging $f$ rom to 40 to $60 \%$. Thus, either body mass index or genetical predisposition to obesity could be key factors to differences in aroma sensing. Besides, oral bacteria are responsible to synthesize a fraction of salivary enzymes (different kinds, dependent on the microorganism type) [29], so it is safe to infer that microbiota profile could play an important part in the described process. According to [30-32], exposing bacteria from three different human oral cavities to odorless glycosides extracted from grape, different results were observed about aromatic molecules release. In fact, while a subject strongly sensed linalool (i.e. a floral and spicy molecule), the others did not, because their bacteria were not able to enzymatically provoke the same phenomenon.

\section{References}

1. Polaskova P, Herszage J, Ebeler SE (2008) Wine flavor: Chemistry in a glass. Chem Soc Rev 37(11): 2478-2489.

2. Liu Y, Rousseaux S, Tourdot Maréchal R, Sadoudi M, Gougeon R (2015) Wine microbiome, a dynamic world of microbial interactions. Crit Rev Food Sci Nutr 57(4): 856-873.

3. Bokulich NA, Collins TS, Masarweh C, Allen G, Heymann, et al. (2016) Associations among wine grape microbiome, metabolome, and fermentation behavior suggest microbial contribution to regional wine characteristics. mBio 7(3): 00631-00616.

4. Bokulich NA, Thorngate JH, Richardson PM, Mills DA (2014) Microbial biogeography of wine grapes is conditioned by cultivar, vintage, and climate. Proc Natl Acad Sci USA 111(1): 139-148.

5. Zarraonaindia I, Owens SM, Weisenhorn P, West K, Hampton-Marcell J, et al. (2015) The soil microbiome influences grapevine-associated microbiota. mBio 6(2): 02527-02614.

6. Gilbert JA, van der Lelie D, Zarraonaindia I (2014) Microbial terroir for wine grapes. Proc Natl Acad Sci USA 111(1): 5-6.

7. Belda I, Ruiz J, Alastruey Izquierdo A, Navascués E, Marquina D, et al. (2016) Unraveling the enzymatic basis of wine flavorome: a phylofunctional study of wine related yeast species. Front Microbiol 7: 12 .

8. Álvarez Pérez JM, Campo E, San Juan F, Coque JJR, Ferreira V, et al. (2012) Sensory and chemical characterisation of the aroma of prieto picudo rosé wines: the differential role of autochthonous yeast strains on aroma profiles. Food Chem 133(2): 284-292.

9. Campbell Sills H, Capozzi V, Romano A, Cappellin L, Spano G, et al. (2016) Advances in wine analysis by PTR-ToF-MS: optimization of the method and discrimination of wines fermented with different malolactic starters. Int J Mass Spectrom 397-398: 42-51.

10. Bartowsky EJ (2005) Oenococcus oeni and malolactic fermentationmoving into the molecular arena. Aust J Grape Wine Res 11(2): 174187.

11. Du Toit M, Engelbrecht L, Lerm E, Weber K, Lactobacillus S (2011) The next generation of malolactic fermentation starter cultures-An overview. Food Bioprocess Technol 4(6): 876-906.

12. Berbegal C, Peña N, Russo P, Grieco F, Pardo I, et al. (2016) Technological properties of Lactobacillus plantarum strains isolated from grape must fermentation. Food Microbiol 57: 187-194.

13. Moreno Arribas MV, Polo MC (2005) Winemaking biochemistry and microbiology: Current knowledge and future trends. Crit Rev Food Sci Nutr 45(4): 265-286.

14. Munoz R, Moreno Arribas M, De las Rivas B (2011) Lactic acid bacteria. In molecular wine microbiology ( $1^{\text {st }}$ edn), Carrascosa AV, Muñoz R, González R (Eds.), Elsevier Academic Press: London, UK, pp. 191-226. 
15. Tao Y, García JF, Sun DW (2014) Advances in wine aging technologies for enhancing wine quality and accelerating wine aging process. Crit Rev Food Sci Nutr 54(6): 817-835.

16. Moreno Arribas V, Pueyo E, Polo MC (1996) Peptides in musts and wines. Changes during the manufacture of cavas (sparkling wines). J Agric Food Chem 44(12): 3783-3788.

17. Alcaide Hidalgo JM, Moreno Arribas MV, Martín Álvarez PJ, Polo MC (2007) Influence of malolactic fermentation, postfermentative treatments and ageing with lees on nitrogen compounds of red wines. Food Chem 103(2): 572-581.

18. Zeng XA, Yu SJ, Zhang L, Chen XD (2008) The effects of ac electric field on wine maturation. Innov Food Sci Emerg 9(4): 463-468.

19. Loira I, Vejarano R, Morata A, Ricardo da Silva J, Laureano O, et al (2013) Effect of Saccharomyces strains on the quality of red wines aged on lees. Food Chem 139(1-4): 1044-1051.

20. Juega M, Carrascosa AV, Martinez Rodriguez AJ (2015) Effect of short ageing on lees on the mannoprotein content, aromatic profile, and sensorial character of white wines. J Food Sci 80(2): 384-388.

21. Belda I, Navascués E, Marquina D, Santos A, Calderón F, et al. (2016) Outlining the influence of non-conventional yeasts in wine ageing over lees. Yeast 33(7): 329-338.

22. Suárez R, Suárez Lepe J, Morata A, Calderón F (2007) The production of ethylphenols in wine by yeasts of the genera Brettanomyces and Dekkera: A review. Food Chem 102(1): 10-21.

23. Bachmanov AA, Bosak NP, Lin C, Matsumoto I, Ohmoto M, et al. (2014) Genetics of taste receptors. Curr Pharm Des 20(16): 2669-2683.
24. The Human Microbiome Project Consortium (2012) Structure, function and diversity of the healthy human microbiome. Nature 486(7402): 207-214.

25. Boehlke C, Zierau O, Hannig C (2015) Salivary amylase: the enzyme of unspecialized euryphagous animals. Arch Oral Biol 60 (8): 1162-1176.

26. Burdach KJ, Doty RL (1987) The effects of mouth movements, swallowing and spitting on retronasal odor perception. Physiol Behav 41(4): 353-356.

27. Genovese A, Piombino P, Gambuti A, Moio L (2009) Simulation of retronasal aroma of white and red wine in a model mouth system. Investigating the influence of saliva on volatile compound concentrations. Food Chem 114 (1): 100-107.

28. Bellman R, Gallander JF (1979) Wine deacidification. Advances in Food Research 25: 1-53.

29. Baliga S, Muglikar S, Kale R (2013) Salivary pH: a diagnostic biomarker. J Indian Soc Periodontol 17(4): 461-465.

30. Piombino P, Genovese A, Esposito S (2014) Saliva from obese individuals suppresses the release of aroma compounds from wine. Plos One 9(1): 85611

31. Derrien M, Van Passel MWJ, Van De Bovenkamp JHB, Schipper RG, De Vos WM, et al. (2010) Mucin-bacterial interactions in the human oral cavity and digestive tract. Gut Microbes 1(4): 254-268.

32. Munoz Gonzales C, Cueva C, Angeles Pozo Bayòn M, Victoria Moreno Arribas M (2015) Ability of human oral microbiota to produce wine odorant aglycones from odourless grape glycosidic aroma precursors. Food Chem 187: 112-119, 